\title{
Elaboração e utilização de Sinais de Libras para os conceitos de Física: Aceleração, Massa e Força
}

Jaqueline Santos Vargas

Shirley Takeco Gobara

\begin{abstract}
Resumo
O presente trabalho tem como tema o Ensino de Física para alunos surdos, especificamente a criação de sinais para conceitos de Física. A partir de uma sequência didática, fundamentada na perspectiva histórico-cultural do desenvolvimento humano, preparamos um grupo de instrutores surdos que elaboraram os sinais para os conceitos de força, aceleração e massa. Também verificamos a aceitação dos novos sinais ao utilizá-los com alguns alunos que frequentavam o Centro de Capacitação de Profissionais da Educação e de Atendimento às Pessoas com Surdez (CAS)-MS e realizamos uma investigação aplicando os novos sinais na discussão das Leis de Newton com esses alunos. Obtivemos os dados por meio de filmagens e gravações de áudio, os quais foram transcritos e analisados usando a Análise Microgenética, fundamentada na perspectiva histórico-cultural de Vygotsky. Os resultados evidenciaram a aceitação dos novos sinais propostos e que o uso desses sinais articulados com aulas interativas e mediadas pelo professor pesquisador contribuíram para a diferenciação entre os conceitos cotidianos e os conceitos científicos para os alunos com surdez investigados.
\end{abstract}

Palavras-chave: Sinais, Ensino de Física, Força, Massa, Aceleração.

\section{Abstract \\ Development and use of Libras signs to the concepts of Physics: Acceleration, Mass and Force}

This present study has as its theme the Physics Teaching for deaf students, specifically the creation of signs for Physics' concepts. From a didactic sequence, based on historical and cultural perspective of human development, we prepared a group of deaf instructors who prepare signs for the concepts of force, mass and acceleration. We also verified the acceptance of new signals with some students who frequent the Training Center of Professional Education and Care for People with Hearing Loss (CAS-MS) and we conducted an investigation applying the new signs in the discussion of Newton's Laws with these students. We obtained data by filming and audio recordings, which were transcribed and analyzed using the Microgenetic Analysis, based on Vygotsky's historical and cultural perspective. The results showed the acceptance of the proposed new signs and that the use of these signs articulated with interactive lessons and mediated by the teacher contributed to the differentiation between quotidian and scientific concepts for students with deafness investigated. 


\section{Introdução}

Em uma pesquisa realizada por Vargas em 2011, ela verificou que os alunos surdos inseridos no contexto escolar das escolas regulares do ensino médio em Campo Grande, MS, têm como apoio para acompanhar as aulas apenas o auxílio dos intérpretes, pois a maioria dos professores, que dão aula em escolas que há alunos surdos, não sabe Libras - Língua Brasileira de Sinais, a primeira língua dos surdos.

Além disso, em entrevistas realizadas com alguns intérpretes de Língua de Sinais da cidade de Campo Grande (VARGAS, 2011), foram notáveis as dificuldades apresentadas por eles para interpretar alguns conceitos de Ciências, em particular da Física. Isto se constitui em um problema porque não existem sinais específicos para vários conceitos de física e os que existem acabam causando certa confusão em função dos conceitos cotidianos, e, muitas vezes, reduz o significado/sentido daquilo que se pretende que o aluno venha a compreender, isto é, os conceitos científicos.

Para nortear a pesquisa usamos os pressupostos da teoria histórico-cultural de Vygotsky (1994). De acordo com esse autor, a relação do indivíduo com o mundo é sempre mediada por alguém ou por algum instrumento ou signos e que os processos mentais superiores têm origem nos processos sociais, ou seja, só a partir da socialização que o sujeito se torna capaz de se desenvolver cognitivamente. Nesse sentido, as relações sociais ajudam a desenvolver as funções superiores por meio dos instrumentos e signos, em que ambos são usados como mediadores para as interações entre os seres humanos, mas também para a interação deles com o mundo.

Para os surdos, a Libras se constitui em um conjunto de signos que são usados para mediar as interações com os ouvintes e com os próprios surdos. Para acontecer as relações de uma maneira que tanto o surdo quanto o ouvinte consigam interagir, sem serem prejudicados por usarem línguas diferentes, acreditamos que é preciso que ambos dominem a Libras, assim como suas regras, e que existam sinais que também sejam familiares ao dia-a-dia do ouvinte.

Por exemplo, a palavra trabalho para pessoas que nunca estudaram Física pode significar emprego, esforço físico ou tarefa escolar. Para os que já estudaram Física, pode representar um conceito físico. $\mathrm{O}$ que acontece com os ouvintes também acontece com os surdos, pois os sinais que significam algo relacionado ao cotidiano do surdo acabam sendo utilizados no contexto escolar, estabelecendo alguns obstáculos para a aprendizagem de conceitos científicos. Dessa maneira, acreditamos que a existência de sinais específicos para conceitos científicos poderá

130 DOI: Em andamento. 
diminuir as dificuldades na interpretação e no entendimento desses conceitos pelo aluno com surdez.

Com vistas às necessidades e dificuldades manifestadas pelos intérpretes em nossa pesquisa anterior (VARGAS, 2011), o escasso número de trabalhos com a temática "sinais de Libras para a Física" e preocupados com a aprendizagem de Física, desenvolvemos uma pesquisa que teve como objetivo a criação de sinais para conceitos de física. Posteriormente, verificamos a aceitação desses sinais com alguns alunos surdos. Buscamos verificar, também, se esses novos sinais podem auxiliar na compreensão dos conceitos científicos.

Essa pesquisa é fruto de discussões e interações com um grupo de surdos e intérpretes que fazem parte do Centro de Capacitação de Profissionais da Educação e de Atendimento às Pessoas com Surdez de Campo Grande, Mato Grosso do Sul (CAS/SED/MS), e que incentivaram e colaboraram no desenvolvimento da nossa proposta.

No presente artigo apresentamos um recorte dessa pesquisa. Inicialmente descrevemos a preparação dos instrutores para a elaboração dos sinais e após discutimos a testagem de um dos sinais criados, para o conceito de forca, realizada com três alunos surdos que frequentavam o CAS.

\section{Procedimentos Metodológicos}

A presente pesquisa é classificada como qualitativa do tipo exploratória, pois testamos os sinais elaborados com um grupo de alunos surdos e um intérprete. Qualitativa, pois procuramos entender o problema a partir da realidade dos participantes e exploratória, pois não existem muitos trabalhos na área e é um tema pouco abordado na área das ciências.

\subsection{Delineamento da Pesquisa}

A pesquisa foi dividida em três etapas. Na primeira etapa houve discussões dos conceitos de força, aceleração e massa com os instrutores surdos para a criação dos sinais. Nessa etapa o ritmo do estudo foi dado pelos participantes, isso porque estávamos preocupados com a apropriação desses conceitos, pois era preciso que o grupo internalizasse os conceitos e seus significados para que os sinais fossem criados.

A segunda etapa tratou da criação e filmagem dos sinais para os conceitos escolhidos. Os sinais foram criados por um grupo de surdos do Centro de Capacitação de Profissionais da Educação e de Atendimento às Pessoas com Surdez (CAS), com a nossa colaboração e coordenação. Entre as atribuiç̧̃es do CAS, por intermédio de sua equipe técnica e dos seus instrutores surdos, destacamos o oferecimento de cursos de Libras em Campo Grande e em 
outros municípios do estado, a capacitação para ensinar Libras para ouvintes, a formação de intérpretes para atuar nas escolas da rede, a elaboração de novos sinais, a divulgação dos mesmos e $o$ atendimento aos alunos surdos (aulas de reforço).

Nessa etapa, inicialmente elaboramos um texto com a definição dos conceitos em Língua Portuguesa. Os intérpretes do grupo estudaram o texto, juntamente com os pesquisadores e traduziram para a Libras. Após esse estudo e discussões, o grupo, constituído por 4 instrutores participantes da pesquisa, elaborou os sinais. Depois da criação dos sinais fizemos um vídeo em Libras com a explicação de cada conceito com exemplos e situações do cotidiano.

A terceira e última etapa, foi a testagem dos conceitos criados com alunos surdos. Elaboramos uma aula equivalente a dois tempos de 50 minutos utilizando os novos sinais e ministramos para alguns alunos surdos voluntários que frequentavam o CAS. A aula foi realizada por nós com a colaboração de um intérprete, como ocorre nas escolas regulares.

\subsection{Sujeitos da Pesquisa}

Em cada uma das etapas da pesquisa, houve participantes diferentes. Na primeira etapa, para as discussões dos conceitos para a criação dos sinais, participaram 23 instrutores surdos, dois intérpretes e uma colaboradora (ouvinte) do curso de Libras do CAS. Para a elaboração dos sinais, a coordenadora pedagógica do CAS/SED/MS acabou selecionando cinco instrutores para a criação dos sinais.

Na segunda etapa, foi realizada a filmagem dos sinais, com a participação dos dois intérpretes e um instrutor surdo.

Na terceira etapa, para a da testagem dos sinais, participaram três alunos surdos e um intérprete.

Em todas as etapas pelo menos um dos pesquisadores (orientador e mestranda) estava presente. Para a identificação dos instrutores surdos usamos a letra $\mathrm{S}$ e um número como índice para indicar diferentes instrutores, por exemplo, instrutor 3 tem a representação $S_{3}$. Da mesma maneira, identificamos os outros sujeitos da pesquisa: a professora (pesquisadora) usamos a letra $P$, os intérpretes letra $I$ e os alunos surdos letra $A$, todos acompanhados pelos números de representação.

\subsection{Opções metodológicas para a coleta dos dados}

Como nossa pesquisa foi baseada na perspectiva histórico-cultural, estávamos interessados nas interações e na mediação que aconteceram durante a aplicação da nossa sequência, além dos discursos gerados pelos alunos durante a nossa investigação. As atividades foram desenvolvidas 
de uma maneira que possibilitava a participação ativa de todos os alunos e instrutores. De acordo com Vygotsky (2000) é por meio da mediação, pelo convívio social e pela linguagem que o aluno se constitui, apropria e elabora conhecimento. Foi baseado nessa premissa que organizamos todos os nossos encontros para a elaboração dos sinais e testagem dos mesmos.

Todas as etapas da pesquisa foram registradas com gravadores digitais e câmera de áudio e vídeo. Além disso, fizemos alguns testes escritos com os instrutores surdos, visando levantar o que eles já sabiam.

Após a obtenção dos dados, eles foram transcritos e separados por episódios nos quais avaliamos qualitativamente usando a Análise Microgenética, que também é baseada na perspectiva histórico-cultural de Vygotsky. Góes (2000, p.9) explica que a Análise Microgenética "trata-se de uma forma de construção de dados que requer a atenção a detalhes e o recorte de episódios interativos (...) resultando num relato minucioso dos acontecimentos". Essa autora defende que todo o processo é importante e não apenas o produto final, assim a Análise Microgenética se encaixa perfeitamente aos nossos propósitos, pois com ela é possível analisar os eventos ocorridos de forma minuciosa, focando nas interações verbais entre os sujeitos e as demonstrações intersubjetivas.

As análises foram feitas, portanto, a fim de buscar indícios que pudessem responder os nossos objetivos, que para este artigo foi verificar a aceitação e utilização dos novos sinais pelos intérpretes e alunos surdos investigados, em particular para o conceito de força.

A pesquisa foi realizada no CAS/SED/MS. Os encontros do grupo para elaboração dos sinais aconteceram em uma sala disponibilizada pela instituição a qual possuía quadro, lousa digital, data show, notebook e carteiras para os integrantes do grupo. A testagem dos sinais foi realizada em uma sala de aula, equipada com os mesmos recursos didáticos, que é utilizada para as aulas de reforço, em contra turno, para os alunos surdos. Contamos com a colaboração de um intérprete, como acontece nas salas de aulas regulares, na qual o professor leciona o conteúdo e o intérprete faz a tradução simultânea para os alunos surdos.

\section{Análises dos Resultados}

Antes dos encontros para as discussões dos conceitos que iríamos criar os sinais, fizemos um levantamento dos conceitos cotidianos dos instrutores surdos, isso porque era importante sabermos o que eles sabiam em relação aos conteúdos que envolviam os conceitos: força, massa e aceleração. 


\subsection{Sistematização do conhecimento científico}

A etapa de sistematização de conhecimento foi o momento para tirar as dúvidas dos instrutores surdos e esclarecer sobre os conceitos escolhidos para que eles criassem os sinais. Para isso, planejamos e elaboramos cinco seções (aulas interativas de aproximadamente quatro horas) utilizando simulações e animações, muitas imagens e exemplos relacionados ao cotidiano dos instrutores para a discussão dos conceitos que eles precisavam se apropriar para criar os sinais. Considerando-se o recorte desse artigo, as discussões que seguem tratam do processo de apropriação dos conceitos pelos instrutores e da testagem dos sinais com alunos surdos. Nos primeiro e segundo encontros, discutimos os conhecimentos prévios dos instrutores com relação aos conceitos de força, massa e aceleração. Verificamos que os instrutores surdos possuíam muitos conceitos espontâneos (cotidianos).

Iniciamos o terceiro encontro introduzindo os conceitos relacionados ao movimento e suas causas por meio de uma interação dialógica, no sentido de estabelecer um diálogo entre o professor pesquisador e os instrutores. Para essa discussão, usamos a simulação do Projeto de simulações interativas da University of Colorado Boulder ${ }^{1}$ (PhET). Esse programa nos possibilitou apresentar e analisar várias situações em que forças constantes eram aplicadas em objetos diferentes com a participação dos instrutores, em que, o tempo todo, eles foram incentivados a manifestar suas opiniões sobre o que aconteceria em cada uma das situações. As interações aconteceram, pois os participantes questionavam porque para certos valores da força aplicada o caixote se movia, porque ia mais rápido e porque ficava parado.

Com essas simulações conseguimos sistematizar os conceitos de causa do movimento, força resultante, aceleração e massa, nessa mesma sequência de conceitos, e finalizamos com a discussão sobre força peso, para diferenciar do conceito de massa.

Ao longo das seções de interações, buscamos observar indícios do processo de apropriação dos conceitos de força, aceleração e massa pelos instrutores surdos, já que eles eram os responsáveis para criar os sinais para esses conceitos. Apresentamos alguns episódios que evidenciam esses indícios e sugerem uma evolução na direção da apropriação desses conceitos.

\section{Episódio 1}

(...)

Pesquisadora: Nesse caso aqui temos um caixote. Como esse caixote está?

$S_{6}:$ Tá parado.

Pesquisadora: Tá parado. Então o que eu faço pra esse objeto se mover?

${ }^{1}$ Disponível em: http://phet.colorado.edu/. Acesso em: fev.2014

134 DOI: Em andamento.

R. Bras. de Ensino de C\&T 
S: Tem que empurrar.

Pesquisadora: O que eu faço pra empurrar ele?

$S_{2}:$ Tem que aplicar uma força.

Pesquisadora: Isso... tem que aplicar uma força...Então eu vou colocar uma força aqui pra ver o que acontece. Aqui é o lugar onde eu coloco a força. Eu vou colocar um valor qualquer.

Pronto, coloquei uma força. O bonequinho está empurrando, mas o objeto não saiu do lugar, o caixote não se moveu.

Vocês sabem explicar por quê?

S7: Porque é pesado.

$S_{17}$ : Porque a pessoa que tá empurrando precisa malhar mais, ele tá fraco, ele tem que ir pra academia, pra depois conseguir empurrar, quando ele for mais forte, ele já viu, magrinho ele não vai conseguir.

Pesquisadora: Então você acha que força está na pessoa?

$S_{17}:$ É... tem que ser forte pra ter força. Magro não consegue.

Pesquisadora: Então você acha que o gordinho consegue? Porque você disse que o magro não consegue.

$S_{17}:$ Ih.... pode ser que o gordo consiga.

(...)

No episódio 1 percebemos que o instrutor 17 está convicto de que a força está na pessoa, ao argumentar que tem que ser forte para possuir essa força. Acabamos estendendo o diálogo contrargumentando a concepção que ele tinha para força, até que ele não conseguisse mais explicar a situação.

Acreditamos que os conceitos cotidianos proporcionam um confronto entre os conceitos científicos em uma situação que poder ser concreta ou não, mas que possa ter uma relação com os conhecimentos do sujeito, assim vai se criando estruturas necessárias para que a evolução aconteça, evolução essa dos aspectos elementares de um conceito. (VYGOTSKY, 2009).

Ao longo da discussão com o instrutor 17 , ele acabou mudando a concepção de força que ele tinha, como podemos observar no episódio 2.

\section{Episódio 2}

\section{$(\ldots)$}

$S_{17}$ Entendi... força é ação. Que pode modificar o movimento de um corpo.

$S_{2}$ : É... é alguma coisa ou alguém...que muda o movimento do corpo. 
Pesquisadora: Isso... é uma ação de um sistema sobre outro...de modo a mudar o seu estado de movimento.

$(\ldots)$

O dialógico desencadeado com a intervenção da pesquisadora e da interação estabelecida, o instrutor 17 acabou mudando a concepção que ele tinha de força. Foi interessante esse processo, pois a partir da aula teórica/dialógica os instrutores participaram constantemente e ao longo das interações e, por meio da linguagem, verificamos em seus argumentos elementos que sugerem que, aos poucos, eles foram se apropriando dos conceitos científicos.

Para cada conceito que apresentávamos fazendo o uso de simulações ou situações do cotidiano, eram feitas perguntas a respeito desse conceito para desencadear o diálogo para que os instrutores pudessem interagir. Fazendo uso dessa metodologia e utilizando a mesma simulação, introduzimos o conceito de massa. A simulação nos permitia mudar os objetos permanecendo a mesma força, e conforme mudávamos os objetos, automaticamente, as massas deles mudavam. Nossa discussão foi no sentido de analisar o que acontecia quando mudávamos a massa e essa força era mantida constante.

Verificamos, como já era esperado, que os instrutores não sabiam diferenciar o conceito de massa do conceito de força peso. Eles usavam os conceitos cotidianos, ao considerarem a massa como peso. Após o diálogo, alguns até souberam usar a palavra massa no contexto correto, porém eles não conseguiram descrever o significado da palavra massa, ao serem questionados.

Continuamos com a intervenção, pois precisávamos que eles se apropriassem dos conceitos de massa e força porque os membros desse grupo é que iriam criar os sinais para esses conceitos.

\section{Episódio 3}

\section{$(\ldots)$}

Pesquisadora: Vimos que um objeto com uma massa menor é mais fácil mover e se o objeto tiver uma massa maior é mais difícil tirar ele do lugar.

Então quanto maior a massa é mais difícil tirar o corpo do lugar, mover.

$S_{3}:$ Verdade, a gente viu isso na simulação.

Pesquisadora: E, essa dificuldade em mover o corpo é chamada de inércia.

$S_{2}:$ Depende da massa.

$S_{4}$ : Antigamente as pessoas faziam pirâmides e as pedras eram muito grandes, elas tinham muita inércia?

Pesquisadora: O que você acha?

S4: Acho que sim... porque acho muito difícil carregar uma pedra daquele tamanho. 
Pesquisadora: Essa dificuldade em mover a pedra é a inércia e a massa é a medida da inércia.

$\boldsymbol{S}_{11}$ : Então quando meço a massa medimos a inércia?

Pesquisadora: É isso... a massa mede a inércia.

Só não podemos confundir massa com peso, porque são coisas diferentes.

(...)

Durante a explicação, por mais que alguns instrutores já estavam se familiarizando com o novo conceito apresentado para eles, o conceito de inércia, outros ainda estavam apegados à concepção de que massa e peso são a mesma coisa, então passamos a discutir sobre força peso e atração gravitacional. No episódio a seguir vemos uma discussão em torno do conceito de peso.

\section{Episódio 4}

\section{(...)}

Pesquisadora: Quando a gente solta um objeto perto da superfície da Terra o que acontece? Oh... vou pegar esse lápis e vou soltar ele...o que acontece?

$S_{2}$ : Ele cai, porque é pesado, a Terra puxa as coisas pesadas.

Pesquisadora: Tá então... ele cai realmente...ele tem uma massa. [...] Na verdade ele cai por causa da força peso, mas não porque o objeto é pesado. Eu vou explicar pra vocês o que acontece e porque acontece.

(...)

Podemos ver no episódio 4 que o instrutor dois continua usando o conceito cotidiano de peso, pois para ele as coisas caem por elas são pesadas. Percebemos que ele não sabia ao certo o que é massa e nem o que é peso. Depois desse episódio, retomamos a intervenção e explicamos o que é a força peso e diferenciamos do conceito de massa. $E$, antes que terminássemos a explicação, o seguinte diálogo foi estabelecido com o instrutor dois.

\section{Episódio 5}

$S_{2}$ : Peso, então é o que a Terra exerce sobre a gente, sobre os materiais, sobre as pessoas. Então nós... a gente não fala nós temos peso.

Pesquisadora: Isso... você tem massa.

$S_{2}$ : Então nós estamos acostumados a falar peso...

Pesquisadora: Isso... no dia a dia...

$S_{2}:$ Temos que trocar... usar certo... 
$S_{2}$ : Nossa... Então tem que perguntar certo...qual é a sua massa...

$S_{3}$ : Então o médico fala tudo errado... ele fala qual é o seu peso é culpa deles.. Ele começa a nos influenciar que estudar...

$S_{4:}$ Justamente, o médico fala qual o seu peso.

$S_{5}:$ Vamos ensinar o médico. É, qual a sua massa.

$(\ldots)$

Percebemos que o instrutor dois, que antes usava o termo pesado como sinônimo de massa, depois da interação e mediação feita pela pesquisadora, conseguiu diferenciar os conceitos de massa e peso, dando indícios da apropriação desses conceitos, argumentando a partir do que a pesquisadora já tinha falado em um momento em que a explicação ainda não tinha sido encerrada. E, o que é melhor, o processo dialógico estabelecido entre ele e a pesquisadora acabou contribuindo e fazendo com que outros instrutores chegassem à mesma conclusão que ele.

A partir da análise microgenética desses episódios foi possível obter indícios de que o conceito de peso que ele tinha era um conceito do cotidiano e que acabou evoluindo para o conceito científico, por meio da mediação feita pela professora pesquisadora. Além disso, esse diálogo foi uma motivação para que os outros instrutores também participassem e dessem suas opiniões a respeito do assunto.

Durante as interações, obtivemos indícios de que a diferenciação entre o conceito de massa e a força peso foi internalizado por alguns instrutores, porém não temos a garantia de que todos os demais instrutores se apropriaram do conceito de massa, visto que este conceito está associado ao entendimento do conceito de inércia que era desconhecido por todos. Por meio dos diálogos interativos não é possível concluir que eles internalizaram o conceito de inércia, mas nas interações registradas nos episódios cinco e seis, podemos verificar que não houve dificuldades na compreensão desse conceito. Embora esse tenha sido o primeiro contato com esse novo conceito, podemos dizer que o primeiro passo para a evolução conceitual foi dado, pois eles já conseguiam reproduzir com suas próprias palavras a explicação dada pela pesquisadora, e para Vygotsky (2009), a aprendizagem dos conceitos científicos pode acontecer, mesmo que seja por meio da imitação de um parceiro mais experiente (capaz), que já passou por esta transição .

\subsection{Elaboração dos sinais}

Antes de criar os sinais, resolvemos apresentar aos instrutores os sinais já existentes para os conceitos que seriam criados, com o intuito de levá-los a conhecer os sinais propostos no Brasil 
e fora do Brasil (VARGAS e GOBARA, 2013) e, também, eles poderiam usar o mesmo sinal ou adaptar o sinal para ser usado no nosso estado ou no nosso país.

Ao se depararem com os sinais de diversos países e até mesmo os nacionais, os surdos não aceitaram aqueles sinais e acabaram rejeitando-os. Para eles, esses sinais não apresentavam nenhuma familiaridade, ou seja, eram sinais que não faziam sentido e que no cotidiano deles representavam outras palavras, além disso, esses sinais não representavam os conceitos que eles haviam discutido e apropriado.

Foi a partir desse momento que eles enfatizaram a importância de se criar os sinais para os conceitos de massa, força e aceleração, como podemos observar na fala do instrutor nove:

$S_{9}:$ O problema é que confunde né, como um sinal é para várias coisas, tem que ficar explicando, agora não é de macarrão é outra massa, massa na Física, nisso a gente tem que ir criando um contexto e é demorado. Por isso é bom quando foca, a gente cria um só pra Física. Ficaria bem mais fácil.

Os instrutores também questionaram alguns sinais que gestualmente está relacionado ao conceito, porém o sinal em si representa outra palavra. Como por exemplo, a fala do instrutor 21 , que questionou um sinal brasileiro para força, que é específico para a Física:

$\boldsymbol{S}_{21}$ : O sinal de força para esse dicionário lembra o sinal de defesa. O gesto parece força, parece que está fazendo um esforço físico, mas o sinal acaba sendo de defesa.

Então para a criação dos sinais, os surdos levaram em consideração os parâmetros da Libras, as regras e também a familiaridade dos sinais com o dia a dia deles, pois é o dia a dia que os inspiram a criarem sinais que tem uma certa familiaridade com o significado do conceito.

O grupo realizou discussões para entender os conceitos e no momento da criação dos sinais, apenas quatro instrutores participaram voluntariamente, e foram aqueles que estavam interessados na proposta. Participaram aqueles que apresentaram melhor desempenho durante as discussões dos conceitos, e, de certa forma, foram aqueles que estavam mais preparados para criar os sinais.

Assim as figuras 1, 2 e 3 representam os sinais criados para aceleração, força e massa respectivamente: 


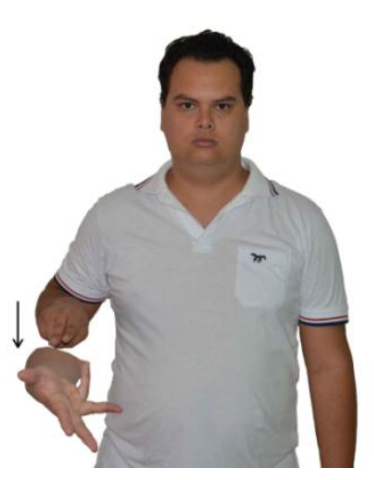

Figura 1 - Sinal de aceleração

(Fonte: Autora)

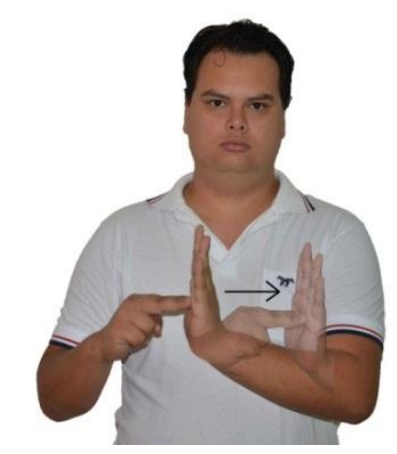

Figura 2 - Sinal de força

(Fonte: Autora)

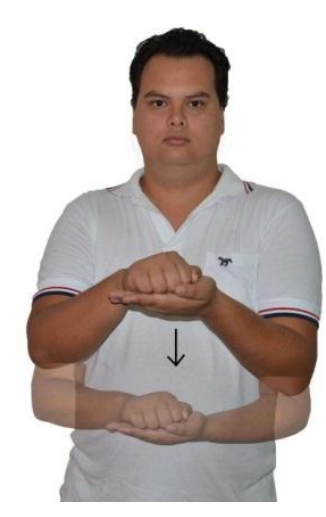

Figura 3 - Sinal de massa

(Fonte: Autora)

\subsection{Utilização e testagem dos sinais criados}


Para a testagem dos sinais criados, elaboramos duas aulas de 50 minutos com o intuito de verificar a aceitação dos sinais pelos alunos surdos e também investigar se os sinais auxiliariam na aprendizagem desses alunos. Três alunos surdos, que frequentam as aulas no CAS, aceitaram voluntariamente participar da pesquisa e um intérprete, como acontece nas salas de aulas regulares, nas quais o professor leciona o conteúdo e o intérprete faz a tradução simultânea para os alunos surdos.

Os sinais foram usados e aplicados ao conteúdo das Leis de Newton. Apresentaremos apenas um episódio, que mostra a aceitação do sinal criado para o conceito de aceleração e os indícios de que se utilizados no contexto da física, juntamente com sua definição, a utilização do sinal pode auxiliar na aprendizagem do aluno. $O$ episódio T1 é sobre o conceito de aceleração, considerando-se o recorte estabelecido para este artigo:

\section{Episódio T1}

$(\ldots)$

Professora: Outro conceito relacionado com a velocidade e importante para iniciar os estudos das leis de Newton é o conceito de Aceleração.

Vocês ouviram falar, no dia a dia, que um carro está acelerado?!

O que significa dizer que o carro está acelerado? Tem a ver com a velocidade?

Quando falamos sobre o conceito de aceleração, a intérprete usou o novo sinal podemos ver a reação dos alunos na continuação do episódio T1.

Aluno B: Que sinal é esse. (Com a cara fechada).

Professora: Esse sinal é novo e é aceleração.

Intérprete: $O$ pessoal do CAS junto com a professora criaram esse sinal, e agora vocês vão poder entender o que é aceleração em física. Ai vocês vão poder usar o novo sinal.

Aluno A: De onde é o sinal?

Professora: Os instrutores surdos criaram o sinal e nós pesquisadores ajudamos apenas nos conceitos de Física. Para eles criarem os sinais, nós ensinamos pra eles o que cada sinal significava na Física.

Aluno A: Nós entender.

Aluno B: Pode usar esse sinal agora na aula de Física.

Intérprete: Nós vamos usar sim.

\section{(...)}


No episódio T1 podemos perceber que o aluno B não gostou da ideia de usar um sinal desconhecido. Além disso, o aluno A questionou a procedência do sinal. Depois que eles souberam como o sinal surgiu, foi que eles aceitaram a utilização do sinal. São os surdos que aceitam e validam os sinais, assim, é normal que quando um novo sinal surge eles questionem e até mesmo não aceitem determinados sinais.

Pela fala do aluno B, "pode usar esse sinal agora na aula de Física", percebemos que houve a aceitação do sinal e os outros alunos acabaram não se manifestando contra. Os instrutores surdos e os intérpretes que participaram da pesquisa afirmaram que vão usar os novos sinais e, além disso, vão divulgar em outros municípios do estado. Nesse sentido, pretendemos realizar uma oficina para preparar os intérpretes para utilizar esses sinais. Essa já é uma prática do CAS para os sinais novos que são elaborados. As discussões sobre a testagem dos conceitos de força e massa serão apresentadas em uma próxima oportunidade.

\section{Considerações Finais}

No desenvolvimento dos encontros, percebemos que os instrutores surdos possuíam muitos conceitos espontâneos, e que, durante as intervenções interativas e dialógicas que realizamos, esses conceitos foram evoluindo, isso porque alguns termos começaram a ser usados por eles em situações de resolução de alguns problemas em que foram exigidos a aplicação desses conceitos. Para Vygotsky (2009), esses instrutores deveriam estar na fase de formação de conceitos, onde eles deveriam operar a palavra como signos, porém percebemos que os sinais e as palavras que representam os conceitos de Física não são compreendidos, uma vez que eles não sabem os conceitos que elas exprimem.

Em geral, uma das dificuldades dos alunos com surdez para conseguir evoluir conceitualmente, e se apropriarem dos conceitos científicos, é que a sua língua é diferente daquele usada pelos professores, assim esse aluno acaba aprendendo superficialmente, baseado apenas no que é concreto (pensamento por complexos), não conseguindo fazer abstrações, já que o professor como mediador do conhecimento, não consegue interagir com esse aluno para auxiliá-lo a construir os conceitos científicos.

Nesse sentido, entramos em outro ponto que é preciso ser pensado que é sobre o ensino praticado para as escolas que recebem alunos surdos. As aulas precisam ser esquematizadas com o intuito de favorecer o aluno com surdez, por meio de estratégias que realmente possam inserir o aluno surdo e favorecer sua aprendizagem, assim como dos ouvintes, minimizando a distância entre o que é ensinado aos ouvintes, na língua materna dele, e o que é ensinado aos alunos surdos. Planejar e desenvolver aulas visuais são maneiras de se aproximar da língua usada pelos surdos. 
Com relação aos conceitos que precisávamos que os instrutores surdos se apropriassem para criar os sinais, tivemos indícios de que eles se apropriaram dos conceitos, principalmente, porque eles conseguiram expor suas ideias usando corretamente as terminologias nas discussões sobre os conceitos de física realizados, evidenciando a capacidade de abstrações desses conceitos, pois mesmo aqueles que já haviam estudado o conteúdo durante a formação básica, verificamos que antes da nossa intervenção, eles usavam apenas conceitos cotidianos.

Já os alunos surdos que participaram da fase de testagem dos sinais, percebemos que eles, embora já tivessem estudado os conceitos de física, quando iniciamos as aulas sobre os conceitos de massa, aceleração e força, verificamos que eles conheciam as palavras relacionadas com a Física, como por exemplo, a palavra gravidade, mas ela era desprovida de significado. Para Vygotsky (2001, p. 184) "a relação entre o pensamento e a palavra é um processo vivo; o pensamento nasce através das palavras. Uma palavra vazia de pensamento é uma coisa morta, e um pensamento despido de palavras permanece uma sombra." Por isso, destacamos a importância de se ensinar o novo sinal, juntamente com o conceito, para que eles consigam construir os significados associados a esses sinais, pois a compreensão da palavra/sinal implica na compreensão do conceito que ela/ele exprime.

Quando os novos sinais foram apresentados aos alunos surdos, percebemos que a preocupação deles estava na credibilidade, isto é, na origem desse sinal. Eles questionaram quem havia inventado o sinal. Foi depois que eles se sentiram mais confiantes, após a explicação da origem desses sinais, eles passaram a se preocupar em entender o que o sinal significava. Consideramos este resultado muito importante, pois percebemos que esses alunos, que participaram da nossa pesquisa, estavam preocupados em aprender realmente. Verificamos que eles já tinham visto o conteúdo nas aulas de física em suas respectivas escolas, mas que não tinham ainda se apropriado desses conceitos, o que confirma um fato bastante recorrente, já levantado em nossa pesquisa anterior (VARGAS, 2011) que alunos surdos acabam passando de série sem a compreensão dos conceitos de Física.

A necessidade da criação de sinais foi apontada pelos próprios surdos, porém o que é necessário é a articulação entre a prática do professor em sala de aula com a maneira que esses novos sinais vão ser inseridos no contexto escolar, pois se não for criada uma estratégia para que os alunos se apropriem dos conceitos que esses sinais representam, teremos mais sinais vazios (sem significados) para os alunos acrescentarem à sua lista de sinais não "aprendidos".

Os resultados sugerem que os novos sinais criados, articulados com aulas interativas e mediadas pelo professor-pesquisador, auxiliaram a aprendizagem dos alunos surdos que participaram voluntariamente dessa pesquisa. Entretanto, não basta produzir os sinais, as aulas devem ser dialógicas e devem ser desenvolvidas utilizando ferramentas visuais, como figuras, vídeos e simulações, já que eles são visuais. Além dessas providências, o intérprete tem que também se apropriar desses sinais para mediar a aprendizagem desses alunos.

R. B. E. C. T., vol 8, Ed. Sinect, jan-abr.2015 ISSN - 1982-873X

DOI: Em andamento. 


\section{Referências}

GÓES, M.C.R. A abordagem microgenética na matriz histórico-cultural: Uma perspectiva para o estudo da constituição da subjetividade. Cadernos Cedes. Campinas: SP, vol.20, Abr. 2000.

VARGAS, J. S. A inclusão do deficiente auditivo em escolas públicas de Campo Grande: as visões do professor, coordenador, intérprete e do aluno. Trabalho de Conclusão de Curso (TCC)-UFMS, Campo Grande, 2011.

VARGAS, J. S.; GOBARA, S. T. Sinais dos conceitos de massa, aceleração e força para surdos na literatura nacional e internacional. Atas do IX Encontro Nacional de Pesquisa em Educação em Ciências (X ENPEC) Águas de Lindóia, 2013.

VIGOTSKI, L.S. A Construção do Pensamento e da Linguagem. Tradução: Paulo Bezerra. -2 ed. São Paulo: Editora Martins Fontes, 2009.

VYGOTSKY, L. S. A Construção do Pensamento e da Linguagem. Tradução: Paulo Bezerra. - 1 ed. São Paulo: Editora Martins Fontes, 2001.

VYGOTSKY, L. S. Princípios de educação social para a criança surda. In: VYGOTSKY, L. S. Obras escolhidas. Tomo 5. Fundamentos de Defectologia. Tradução por Prof. Dr. Adjuto de Eudes Fabri, 1994. Disponível em: <http://pt.scribd.com/doc/16420056/Vigotski-Principios-de-educacaosocial-para-a-crianca-surda-traduzido-por-AE-Fabri>. Acesso em: dez. 2013.

VYGOTSKY, L.S. Formação social da mente. São Paulo: Martins Fontes. 2000. (Texto original, 1984).

Jaqueline Santos Vargas - Professora Adjunta da Anhanguera Uniderp - Campo Grande. Mestre em Ensino de Ciências pela Universidade Federal de Mato Grosso do Sul. Graduada em Física Licenciatura pela Universidade Federal de Mato Grosso do Sul. E-mail: jkvargas-@hotmail.com

Shirley Takeco Gobara - Professora Titular. Doutora em Didática das Disciplinas Científicas pela Université Claude Bernard-Lyon 1. Coordenadora do Programa de Pós-Graduação em Ensino de Ciências da UFMS. Professora e pesquisadora do Programa de Pós-Graduação em Educação da UFMS. E-mail: stgobara@gmail.com 